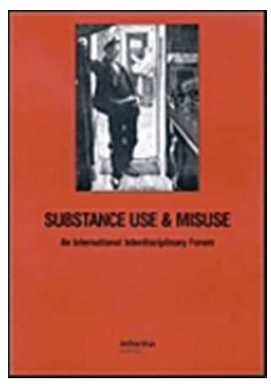

\title{
Attitudes and perceived social norms towards drug use among gay and bisexual men in Australia
}

\begin{tabular}{|r|l|}
\hline Journal: & Substance Use and Misuse \\
\hline Manuscript ID & LSUM-2018-0261.R1 \\
\hline Manuscript Type: & Original Paper \\
\hline Keywords: & $\begin{array}{l}\text { attitudes, chemsex, men who have sex with men, norms, sexual practices, } \\
\text { substance use }\end{array}$ \\
\hline \multicolumn{2}{|l}{} \\
\hline
\end{tabular}

SCHOLARONE $^{\text {M }}$

Manuscripts 


\title{
Attitudes and perceived social norms towards drug use among gay and bisexual men in Australia
}

\begin{abstract}
Background: Gay and bisexual men (GBM) report distinctive patterns and contexts of drug use, yet little has been published about their attitudes towards drug use.

Objectives: We developed measures of attitudes and perceived social norms towards drug use, and examined covariates of more accepting attitudes and norms among GBM in Australia.

Methods: We analysed baseline data from the [removed for blinded review] study. This is an online prospective observational study of drug use among Australian GBM. We used principal components factor analysis to generate two attitudinal scales assessing "drug use for social and sexual enhancement" and "perceptions of drug risk". A third perceived social norms scale examined "acceptability of drug use among gay friends".

Results: Among 2,112 participants, $61 \%$ reported illicit drug use in the preceding 6 months. Stronger endorsement of drug use for social and sexual engagement and lower perceptions of drug risk were found among men who were more socially engaged with other gay men and reported regular drug use and drug use for sex. In multivariate analyses, all three scales were associated with recent drug use (any use in the previous six months), but only the drug use for social and sexual enhancement scale was associated with regular (at least monthly) use.
\end{abstract}

Conclusions: Drug use and sex are difficult to disentangle for some GBM, and health services and policies could benefit from a better understanding of attitudinal and normative factors associated with drug use in gay social networks, while recognising the role of pleasure in substance use.

Keywords: substance use; men who have sex with men; attitudes; norms; chemsex; sexual practices 


\section{Introduction}

Gay and bisexual men (GBM) typically report higher rates of illicit drug use compared to heterosexual men (McCabe, Hughes, Bostwick, West, \& Boyd, 2009; Roxburgh, Lea, de Wit, \& Degenhardt, 2016). In a recent population survey, Australian GBM had twice the odds of reporting illicit drug use in the previous 12 months compared to heterosexual men ( $36 \%$ vs $17 \%)$ and were twice as likely to have ever sought professional assistance for alcohol and other drug issues (12\% vs $6 \%$ ) (Roxburgh et al., 2016). A common theory for the higher prevalence of substance use and problems from use experienced by GBM is minority stress, in which some GBM experience chronically elevated social stress because of perceived and enacted stigma towards sexual minorities, which can have an additive effect on general psychosocial stressors, increasing the susceptibility of poor mental health and issues with substance use (Meyer, 2003).

Historically, GBM in Australia and other Western countries also had few spaces to be open about their sexuality because of social stigma and the illegal status of homosexuality (D'Emilio, 1983; Reynolds, 2002). As a consequence, bar and nightclub cultures catering to GBM developed in specific neighbourhoods that provided safe settings to meet friends and sexual and romantic partners (Faderman, 1992; Wotherspoon, 1991). As bars and nightclubs are common settings for substance use, alcohol and other drugs have played an important role in the formation of gay social networks and communities (Lewis \& Ross, 1995; Race, 2009; Southgate \& Hopwood, 2001). Drugs have also featured in the sexual lives of many GBM, where they are used to facilitate sex and enhance sexual pleasure (Bourne, Reid, Hickson, Torres-Rueda, \& Weatherburn, 2015; Green \& Halkitis, 2006; Isaiah Green, 2003). GBM who report using drugs for sex are more likely to report engaging in practices associated with HIV transmission such as condomless sex with casual partners, a high number of recent sexual partners and group sex (Hurley \& Prestage, 2009). More recently, crystal methamphetamine, gamma-hydroxybutyrate (GHB) and mephedrone (primarily in Europe) have become popular among GBM who use drugs for sex, now commonly known as 
"chemsex" (Bourne et al., 2015; Hammoud et al., 2018). These changes in drug use practices and settings may have led to shifts in attitudes and perceived social norms.

In distinguishing between attitudes and perceived social norms, attitudes can be understood as "the degree to which a person has a favourable or unfavourable evaluation or appraisal" of a particular behaviour (Ajzen, 1991, p. 188), while perceived social norms refer to beliefs about whether "important referent individuals or groups approve or disapprove of performing a given behavior" (p. 195). Lesbian, gay and bisexual people report more accepting attitudes towards drug use than heterosexuals, and are more likely to perceive that drugs are easily available (Cochran, Grella, \& Mays, 2012). The "gay neighbourhood drug subculture hypothesis" suggests that GBM who live in areas with a high number of gay residents and have social networks primarily composed of gay men are more likely to report regular drug use (Carpiano, Kelly, Easterbrook, \& Parsons, 2011). Research has tended to corroborate this hypothesis. In Australia, GBM who are highly socially engaged with gay men have been more likely to report recent drug use than men who are not (Prestage, Hammoud, Lea, Jin, \& Maher, 2017), and GBM who report that most or all of their friends were gay men have been more likely than those who did not to report recent crystal methamphetamine use (Lea et al., 2016).

Few quantitative studies have examined attitudes and perceived social norms towards drug use among GBM, and no scales are in common use. Most research has examined motivations for drug use at dance parties and in sexual contexts (Halkitis, Mukherjee, \& Palamar, 2007; Mansergh et al., 2001; Ross, Mattison, \& Franklin Jr, 2003), and more recently, drug-use sensation seeking (Prestage et al., 2017). Some of this work has been informed by measures of sexual sensation-seeking developed as indicators of sexual risk practices associated with HIV transmission among GBM (Kalichman \& Rompa, 1995). Understanding attitudinal and normative factors associated with drug use among GBM is important to ensure that harm reduction, drug treatment and sexual health services can 
provide culturally appropriate and non-stigmatising services to GBM that also acknowledge that men will have diverse motivations for using drugs (Race, 2009).

This paper has two aims: i) develop measures of attitudes and perceived social norms towards drug use among GBM; and ii) utilise these measures to examine sociodemographic characteristics, sexual and drug use practices associated with more accepting attitudes and social norms among Australian GBM.

\section{Methods}

The [removed for blinded review] study is an online, prospective observational study examining drug use among GBM in Australia. The study design and methods have been described previously [removed for blinded review].

\section{Sample and recruitment}

Briefly, men were eligible to participate in the study if they were at least 16 years of age, identified as gay, bisexual or had sex with a man in the previous 12 months, and lived in Australia(16 was the minimum age for eligibility, consistent with the age of consent in most Australian jurisdictions). Baseline recruitment was conducted in two phases, from September 2014 to July $2015(n=2,214)$ and February-July $2017(n=1,039$; total $N=3,253)$. All recruitment was conducted online via advertisements on Facebook and social and sexual networking websites/apps popular among GBM, and via gay community organisations and gay social events. No remuneration was offered. Ethical approval was received from [removed for blinded review].

\section{Measures}

Questions about sociodemographic characteristics, drug use, HIV testing and status, and sexual practices were adapted from national behavioural surveillance surveys of GBM in Australia (Holt et al., 2017). Participants reported whether they had ever used a range of 
drugs and how often they had used each drug in the previous six months (never, once/twice, at least monthly, every week, daily). Alcohol consumption was assessed using the Alcohol Use Disorders Identification Test - Consumption (AUDIT-C), and participants were assigned to one of four alcohol-risk categories based on their score $(0=a b s t i n e n t ; 1-4=l o w ; 5-$ 8=moderate; 9-12=high) (Harris, Bradley, Bowe, Henderson, \& Moos, 2010). Six questions about specific sex practices with casual male partners were used to determine whether participants had no anal intercourse, consistent condom use or any condomless anal intercourse with casual male partners (Holt et al., 2017).

Sixteen items were devised by the researchers to assess attitudes towards drug. Participants indicated their agreement with each item on 6-point Likert scale (1=strongly disagree, 6=strongly agree) (Table 2).Nine additional items assessing perceived social norms asked about the acceptability of the use of specific drugs among gay friends ("How acceptable is it among your gay friends to use [name of drug]?") on a 4-point Likert scale (1=not at all acceptable, 4=very acceptable) (Table 3).

\section{Statistical analyses}

Analyses were restricted to participants who completed all questions on attitudes towards drug use and acceptability of drug use among gay friends ( $n=2,112,64.9 \%)$. Compared to participants who did not complete these items $(n=1,141)$, men who completed all items $(n=2,112)$ were more likely to be Australian born $(79.6 \%$ vs. $76.2 \% ; p=.025)$, to have completed a university degree $(57.4 \%$ vs. $49.3 \%$; $p<.001)$, to report that most or all of their friends were gay men $(32.0 \%$ vs. $25.2 \%$; $p<.001)$, to be in a relationship $(37.5 \%$ vs. $30.1 \%$; $p<.001)$, to report condomless anal intercourse with casual male partners in the previous six months $(36.8 \%$ vs. $27.7 \%$; p<.001), and to have ever used illicit drugs $(85.9 \%$ vs. $72.4 \%$; $\mathrm{p}<.001)$. 
We conducted principal components factor analysis using a polychoric correlation matrix to determine whether the 16 attitude items could form reliable and conceptually meaningful scales. Polychoric methods are appropriate when conducting factor analyses with ordinal scales and variables that are highly skewed or have high kurtosis (Flora \& Curran, 2004). This resulted in a two-factor solution that accounted for $83.4 \%$ of the total variance (Table 2). The first factor comprised 5 items that measured perceptions and experiences of "drug use for social and sexual enhancement", and had good internal consistency to form a scale $(\alpha=.83)$. The second factor also formed a reliable scale $(\alpha=.81)$ with 3 items that measured "perceptions of drug risk". Mean scores on each scale ranged from 1 (strong disagreement) to 6 (strong agreement). Higher "drug use for social and sexual enhancement" scores meant participants were more likely to endorse drug use for those purposes. Mean scores for items on the "perceptions of drug risk" scale were reversed for ease of comprehension, so that higher scores meant that participants were more likely to regard drug use as risky.

A third social norms scale was created using the nine items about "acceptability of drug use among gay friends" ( $\alpha=.90)$ which were not included in the factor analysis. The scale score created from the mean of these items ranged from 1 (not at all acceptable) to 4 (very acceptable). Bivariate linear regression was used to examine associations between scores on each of the three scales and participants' sociodemographic characteristics and sexual and drug use practices. Pearson's correlation coefficients were calculated to determine the direction and strength of association between the three scales, and between each scale and a previously published "drug use sensational-seeking scale" that identified men interested in more "adventurous and risky drug use" (Prestage et al., 2017, p. 74). This scale was developed for the [removed for blinded review] based on a well-known measure of sexual sensation-seeking (Kalichman \& Rompa, 1995).

Multivariate logistic regression was then used to determine the degree of independent association between the two attitudes scales, the perceived social norms scale and i) recent 
illicit drug use (any drug use in the previous six months), ii) regular illicit drug use (at least monthly illicit drug use in the previous six months, compared to use in the previous six months less often than monthly), iii) recent crystal methamphetamine use (any use in the previous six months), and iv) regular crystal methamphetamine use (at least monthly use). Alpha was set at .05.. Analyses were conducted using Stata SE Version 13.1.

\section{Results}

Sample characteristics

The mean age of participants was 34.7 years $(S D=12.9)$ and $99.0 \%$ were cisgender men. Most participants (89.7\%) identified as gay and $7.9 \%$ identified as bisexual. The majority had completed a university degree (57.4\%), were full-time employed (57.1\%) and were born in Australia (79.6\%). Most participants reported that they were HIV-negative when last tested (76.8\%), $7.0 \%$ were HIV-positive and $16.2 \%$ were untested or did not know their HIV status.

Thirty-one percent of participants reported that most of their friends were gay men, and $22.3 \%$ reported spending "a lot" of time with gay male friends. Thirty-eight percent reported being in a relationship with a male partner, $66.7 \%$ reported having one or more casual male sex partners in the previous six months, and $36.8 \%$ reported condomless anal intercourse with casual male partners in the previous six months.

Most participants (85.9\%) reported having ever used an illicit drug and $61.0 \%$ reported use in the previous six months. More than one third (35.7\%) reported at least monthly and $17.0 \%$ at least weekly illicit drug use. Ten percent of participants reported feeling that they currently had a "problem with drugs".

Fourteen percent of participants reported crystal methamphetamine use in the previous six months, $6.2 \%$ in the previous month. Among men who reported recent crystal methamphetamine use (previous six months), the majority (86.0\%) reported using drugs for 
sex during this period, and $39.4 \%$ reported feeling that they currently had a problem with drugs.

\section{Attitudes and perceived social norms towards drug use}

The mean score on the drug use for social and sexual enhancement scale was 2.91 $(S D=1.16)$. Twelve percent of participants agreed or strongly agreed with at least four of the five items, while only eight participants $(0.4 \%)$ agreed or strongly agreed with all items. Twenty-three percent of participants disagreed or strongly disagreed with all items. The mean score on the perceptions of drug risk scale was $3.08(S D=1.30)$. Twenty-two percent agreed or strongly agreed with all items, and $9.3 \%$ disagreed or strongly disagreed with all items.

Eighty percent of participants reported that at least "a few" of their gay friends used illicit drugs, and $22.2 \%$ reported that "most" or "all" of their gay friends did. The mean score on the acceptability of drug use among gay friends scale was $2.14(S D=0.74)$, indicating moderate perceived acceptance of drug use among participants' gay friends (i.e., between "slightly" and "somewhat" acceptable). The level of acceptability varied between different drugs, with more than half of participants reporting that their gay friends had "somewhat" or "very" accepting attitudes towards cannabis (73.2\%), amyl nitrite (67.4\%) and ecstasy $(56.9 \%$; Table 3). Other drugs were perceived to be less acceptable, with more than half reporting that the following drugs were "not at all" acceptable among their gay friends: heroin $(90.5 \%)$, crystal methamphetamine (64.1\%), gamma-hydroxybutyrate $(56.2 \%)$ and ketamine $(55.8 \%)$.

Higher mean scores on the drug use for social and sexual enhancement and acceptability of drug use among gay friends scales and lower scores on the perceptions of drug risk scale were associated with participants being older, HIV-positive, in a relationship, had mostly or all gay friends, spent a lot of time with gay friends, had anal intercourse with casual partners, had group sex, consumed alcohol at riskier levels, used illicit drugs recently or regularly, 
used crystal methamphetamine recently or regularly, and used drugs for sex (Table 4). Participants who did not know their HIV status had lower scores on the drug use for social and sexual enhancement and acceptability of drug use among gay friends scales and higher scores on the perceptions of drug risk scale compared to HIV-negative participants. Bisexual participants had lower scores on the acceptability of drug use among gay friends scale, and participants whose sexual identity was not gay or bisexual had lower scores on the perceptions of drug risk scale. Lower scores were also reported on the acceptability of drug use among gay friends and perception of drug risk scales among those who had completed a university degree compared to those who had not (Table 4).

\section{Covariates of illicit drug use}

Drug use for social and sexual enhancement had a strong negative correlation with the perceptions of drug risk ( $r=-.60$ ), and a positive correlation with acceptability of drug use among gay friends $(r=.66)$. There was a moderate negative correlation between perceptions of drug risk and acceptability of drug use among gay friends ( $r=-.50)$. There was a very strong positive correlation between the previously published drug use sensation-seeking scale and drug use for social and sexual enhancement $(r=.80)$, a moderate negative correlation with perceptions of drug risk $(r=-.55)$ and a strong positive correlation with acceptability of drug use among gay friends ( $r=.66)$.

In bivariate analyses, higher drug use for social and sexual enhancement scores and acceptability of drug use among gay friends scores, and lower perceptions of drug risk scores were observed among participants who reported illicit drug use in the previous six months (compared to all other participants), and participants who reported at least monthly drug use in the previous six months (compared to participants who reported less than monthly drug use in the previous six months; Table 5). In multivariate analyses controlling for potentially confounding variables, all three scales were positively associated with drug use in 
the previous six months, but only the drug use for social and sexual enhancement scale was associated with monthly or more frequent drug use in the previous six months.

In bivariate analyses, higher drug use for social and sexual enhancement scores and acceptability of drug use among gay friends scores were associated with crystal methamphetamine use in the previous six months and at least monthly use in the previous six months, while lower perceptions of drug risk scores were associated with crystal methamphetamine use in the previous six months, but not with monthly or more frequent use (Table 5). In multivariate analyses, drug use for social and sexual enhancement and acceptability of drug use among gay friends were positively associated with crystal methamphetamine use in the previous six months, and drug use for social and sexual enhancement was positively associated with monthly or more frequent crystal methamphetamine use.

\section{Discussion}

We developed three scales to assess attitudes and perceived social norms towards drug use among GBM. This was a drug-experienced sample, reflected in generally accepting attitudes towards illicit drug use and perceptions that drug use was relatively acceptable within participants' gay social networks. There was some attitudinal variation, with stronger endorsement of drug use for social and sexual enhancement and lower perceptions of drug risk found among men who were more socially engaged with other gay men, and among those who reported regular drug use, drug use for sex, and sexual practices often associated with HIV transmission (e.g., condomless anal intercourse with casual partners, group sex) (Bourne et al., 2015; Prestage et al., 2009). Men who were untested or of unknown HIV status had less accepting attitudes towards drug use and were less likely to perceive that drug use was normative among their gay friends, which corresponds with lower rates of drug use reported among these men in the [removed for blinded review]. Future analyses of this cohort may explore drug use by HIV status in more detail. 
Recent use of any drug and recent crystal methamphetamine use were associated with more accepting attitudes towards drug use when controlling for potential sociodemographic and behavioural confounders. However, only the drug use for social and sexual enhancement scale differentiated between people who used drugs recently (past 6 months) and regularly (at least monthly). This suggests a more prominent role of pleasure and enhancement in motivating GBM who regularly use drugs compared to those who use less frequently, where the pleasure derived from drug use may outweigh perceptions of risk and social norms within friendship networks (Dwyer, 2008; Pennay \& Moore, 2010; Power et al., 2018; Race, 2009). These findings also support the concept of sex-based sociality, in which men use sex and drugs as "social resources around which to build identities, establish relationships, participate in gay communities, and maximise pleasure" (Bryant et al., 2018, p. 242). While perceived social norms may be "a powerful influence on the health behaviors that individual men adopt" (Mahalik, Burns, \& Syzdek, 2007, p. 2202), research on drug use norms among GBM suggest that proximal, rather than distal, groups are more influential on patterns of substance use (Hamilton \& Mahalik, 2009). Men with whom participants use drugs in sexual contexts may be more proximal than gay friends with whom drugs are used only in social settings used irregularly or reserved for special occasions This may help to explain the differences we found between participants reporting recent and regular drug use, and the absence of differences in perceptions of drug risk and perceived norms among gay friends.

The three scales had good correlations with our previously developed drug use sensationseeking scale, which was devised to predict risky drug use and sex practices, especially the initiation of risky practices (Prestage et al., 2017). Our new measure of drug use for social and sexual enhancement will likely have a broader use in identifying the extent to which drug use and sex partying were undertaken specifically for the pursuit of pleasure (Hurley \& Prestage, 2009). 
Most participants reported having gay friends that used illicit drugs, one in five men said that most or all of their gay friends used drugs, and most participants perceived that their gay friends had accepting attitudes towards at least some drug types. This suggests that drug use is fairly normative within gay social networks in Australia. However, this could be inflated by the high rates of drug use in our sample, as participants who did not report recent use had less accepting attitudes, and participants who did not complete the items on attitudes and norms were less likely to report drug use. While acceptability of drug use was considerably higher than in the Australian general population (AlHW, 2017), some drugs were considered more acceptable than others, and these patterns tended to reflect those in the general population. In both our study and the wider community, heroin and crystal methamphetamine were considered the least acceptable drugs, while cannabis was seen as the most acceptable (AlHW, 2017). Despite the higher prevalence of methamphetamine use among GBM compared to heterosexual men (Roxburgh et al., 2016) and crystal methamphetamine often being portrayed as a "gay drug" (Reback, 1997; Schwartz \& Willis, 2009), most GBM do not use it and few study participants reported that methamphetamine use was acceptable among their gay friends. The discrepancy between the prevalence of methamphetamine use and its acceptability among gay friends, coupled with both gay and mainstream media portrayals of crystal methamphetamine that often reinforce stigmatising attitudes (Chalmers, Lancaster, \& Hughes, 2016; Lloyd, 2013; Scheibe, 2017; Schwartz \& Willis, 2009), could discourage GBM experiencing problems with use from seeking help, particularly informally from peers, and be difficult to reach with harm reduction initiatives.

Our study has limitations. Questions about drug use attitudes were presented at the end of the survey as an opt-in section, and some participants did not complete this section or completed only some questions. Participants who completed this section were more likely to report drug use and condomless sex, and were more socially engaged with gay men. This may have inflated the proportion of men who reported accepting attitudes and social norms. While we developed three reliable scales that can be used in longitudinal analyses of the 
present cohort and in other studies, several items did not load on any factor. While ours was a relatively drug-experienced sample, the prevalence of drug use was similar to Australian GBM in behavioural surveillance surveys (Lea et al., 2013). Nevertheless, the findings may not be generalisable to all Australian GBM.

The distinctive patterns of drug use and risk practices reported by GBM often require tailored policy and programmatic responses, such as integrated harm reduction and sexual health services (Bourne et al., 2015; Stardust, Kolstee, Joksic, Gray, \& Hannan, 2018). Drug use and sex are difficult to disentangle for some GBM, and policies and programs that respond to their needs can benefit from a better understanding of drug use norms within gay social networks. To more effectively engage GBM, policies and programs should acknowledge the role of pleasure in substance use, and the social and relational benefits that using substances can confer (Peterson \& Bakeman, 2006; Power et al., 2018; Race, Lea, Murphy, \& Pienaar, 2017). Studies of other populations such as young people and clubbers have also reported that substance use often enhances confidence, sociability and strengthens social ties (Bryant, Ellard, Fisher, \& Treloar, 2012; Olsen, 2009; Sayette et al., 2012). While substance use can result in harms, interventions that frame substance use as inherently risky or pathological may have the unintended consequence of alienating GBM from accessing services. 
Table 1. Polychoric and Pearson's correlation matrices of attitudes towards drug use items $(n=2,112)$

\begin{tabular}{|c|c|c|c|c|c|c|c|c|}
\hline & Item & & & & & & & \\
\hline & 1 & 2 & 3 & 4 & 5 & 6 & 7 & 8 \\
\hline $\begin{array}{l}\text { 1. I use drugs to fit into the } \\
\text { gay scene }\end{array}$ & 1 & .63 & .50 & .44 & .52 & .24 & .38 & .30 \\
\hline $\begin{array}{l}\text { 2. I enjoy being able to use } \\
\text { drugs with my gay friends }\end{array}$ & .46 & 1 & .65 & .56 & .70 & .46 & .59 & .53 \\
\hline $\begin{array}{l}\text { 4. I think party drugs help } \\
\text { gay men have more } \\
\text { intensely pleasurable } \\
\text { experiences }\end{array}$ & .32 & .48 & .69 & 1 & .53 & .39 & .47 & .43 \\
\hline $\begin{array}{l}\text { 7. Occasional use of drugs } \\
\text { is not really dangerous }\end{array}$ & .27 & .51 & .49 & .44 & .56 & .60 & 1 & .66 \\
\hline $\begin{array}{l}\text { 8. Many things are much } \\
\text { more risky than trying } \\
\text { drugs }\end{array}$ & .21 & .45 & .39 & .39 & .48 & .56 & .62 & 1 \\
\hline
\end{tabular}

Polychoric correlations are above the diagonal; Pearson's correlations are below the diagonal. 
Table 2. Polychoric principal components analysis on attitudes towards drug use among gay and bisexual men $(n=2,112)$

\begin{tabular}{|c|c|c|c|c|c|c|c|c|}
\hline & \multicolumn{4}{|c|}{ Endorsement of each item (\%) } & \multirow[b]{2}{*}{ M (SD) } & \multicolumn{3}{|c|}{ Principal components analysis } \\
\hline & Disagree & $\begin{array}{l}\text { Slightly } \\
\text { disagree }\end{array}$ & $\begin{array}{l}\text { Slightly } \\
\text { agree }\end{array}$ & Agree & & $\begin{array}{l}\text { Factor } \\
\text { loading }\end{array}$ & Eigenvalue & $\begin{array}{l}\% \text { of } \\
\text { variance }\end{array}$ \\
\hline \multicolumn{9}{|l|}{ Factor $1(\alpha=.83)$ : Drug use for social and sexual } \\
\hline enhancement & & & & & & & 4.25 & 50.0 \\
\hline I use drugs to fit into the gay scene & 88.7 & 5.1 & 4.6 & 1.6 & $1.49(0.92)$ & .64 & & \\
\hline I enjoy being able to use drugs with my gay friends & 55.5 & 5.9 & 17.2 & 21.4 & $2.66(1.78)$ & .74 & & \\
\hline \multicolumn{9}{|l|}{ Using party drugs with gay men makes for great } \\
\hline sex & 46.7 & 10.7 & 22.7 & 19.8 & $2.94(1.60)$ & .79 & & \\
\hline \multicolumn{9}{|l|}{ I think party drugs help gay men have more } \\
\hline intensely pleasurable experiences & 34.2 & 13.1 & 31.6 & 21.1 & $3.26(1.51)$ & .72 & & \\
\hline The idea of using drugs makes me feel good & 50.0 & 15.1 & 19.2 & 15.8 & $2.74(1.56)$ & .69 & & \\
\hline Factor $2(\alpha=.81)$ : Perceptions of drug risk & & & & & & & 2.84 & 33.4 \\
\hline Not all drug use is addictive & 18.1 & 8.3 & 21.2 & 52.5 & $2.82(1.56)$ & .69 & & \\
\hline Occasional use of drugs is not really dangerous & 26.3 & 15.0 & 26.0 & 32.7 & $3.38(1.53)$ & .69 & & \\
\hline Many things are much more risky than trying drugs & 18.2 & 14.4 & 25.5 & 41.8 & $3.03(1.48)$ & .69 & & \\
\hline
\end{tabular}


Table 3. Participants' perceptions of the acceptability of different drugs among their gay friends $(n=2,112)$

\begin{tabular}{lrrrr}
\hline & \multicolumn{4}{c}{ Level of acceptability (\%) } \\
\cline { 2 - 5 } Drug & Not at all & Slightly & Somewhat & Very \\
\hline Amyl nitrite & 15.7 & 16.9 & 23.6 & 43.8 \\
Cannabis & 9.8 & 17.0 & 30.5 & 42.7 \\
Ecstasy & 24.5 & 18.6 & 30.4 & 26.4 \\
Cocaine & 36.6 & 19.8 & 21.4 & 22.3 \\
Speed (methamphetamine & & & & \\
powder) & 39.2 & 24.2 & 21.5 & 15.1 \\
Ketamine & 55.8 & 20.2 & 14.8 & 9.2 \\
Gamma-hydroxybutyrate (GHB) & 56.2 & 21.8 & 13.9 & 8.1 \\
Crystal methamphetamine & 64.1 & 20.1 & 10.5 & 5.3 \\
Heroin & 90.5 & 6.8 & 1.9 & 0.8 \\
\hline
\end{tabular}


Table 4. Bivariate associations between sociodemographic characteristics and mean scores on drug use for social and sexual enhancement scale and perceptions of drug risk scale $(n=2,112)$

\begin{tabular}{|c|c|c|c|c|c|c|c|}
\hline & \multirow[b]{2}{*}{$\%$} & \multicolumn{2}{|c|}{$\begin{array}{l}\text { Drug use for social } \\
\text { and sexual } \\
\text { enhancement scale }\end{array}$} & \multicolumn{2}{|c|}{$\begin{array}{l}\text { Perceptions of drug } \\
\text { risk scale }\end{array}$} & \multicolumn{2}{|c|}{$\begin{array}{l}\text { Acceptability of drug } \\
\text { use among gay friends } \\
\text { scale }\end{array}$} \\
\hline & & $M(S D)$ & $\beta$ & $M(S D)$ & $\beta$ & M (SD) & $\beta$ \\
\hline \multicolumn{8}{|l|}{ Age group (years) } \\
\hline $16-24$ & 25.4 & $2.28(1.07)$ & Ref. & $3.34(1.34)$ & Ref. & $1.80(0.65)$ & Ref. \\
\hline $25-29$ & 18.4 & $2.59(1.15)$ & $.10^{\star \star *}$ & $3.05(1.24)$ & $-.09^{\star *}$ & $2.14(0.71)$ & $.17^{* \star *}$ \\
\hline $30-39$ & 24.0 & $2.70(1.20)$ & $.15^{\star \star *}$ & $2.98(1.33)$ & $-.12^{* \star \star}$ & $2.30(0.75)$ & $.29^{* \star \star}$ \\
\hline $40-49$ & 16.3 & $3.01(1.18)$ & $.23^{\star \star \star}$ & $2.86(1.23)$ & $-.13^{* * *}$ & $2.43(0.72)$ & $.31^{* \star *}$ \\
\hline 50 or older & 15.9 & $2.68(1.10)$ & $.12^{\star \star \star}$ & $3.05(1.26)$ & $-.08^{* *}$ & $2.13(0.71)$ & $.16^{* \star *}$ \\
\hline \multicolumn{8}{|l|}{ Sexual identity } \\
\hline Gay & 89.7 & $2.62(1.16)$ & Ref. & $3.08(1.30)$ & Ref. & $2.15(0.74)$ & Ref. \\
\hline Bisexual & 7.9 & $2.60(1.13)$ & -.004 & $3.19(1.36)$ & .02 & $1.95(0.71)$ & $-.07^{* *}$ \\
\hline Different identity & 2.4 & $2.78(1.22)$ & .02 & $2.59(1.06)$ & $-.06^{* *}$ & $2.29(0.87)$ & .03 \\
\hline \multicolumn{8}{|c|}{ Completed university degree } \\
\hline No & 42.6 & $2.59(1.18)$ & Ref. & $3.21(1.36)$ & Ref. & $2.08(0.76)$ & Ref. \\
\hline Yes & 57.4 & $2.64(1.15)$ & .02 & $2.98(1.24)$ & $-.09^{* \star *}$ & $2.18(0.72)$ & $.06^{\star *}$ \\
\hline
\end{tabular}


HIV status

\section{Negative}

Positive

Untested/unknown

Relationship status

No relationship

In a relationship

Gay friends

None or some

Most or all

Time spent with gay friends

None or some

A lot

Anal intercourse with casual

male partners in past $6 \mathrm{~m}$

No partners / no intercourse

Consistent condom use

Any condomless intercourse

Group sex in past $6 \mathrm{~m}$

$\begin{array}{rllllll}76.8 & 2.66(1.15) & \text { Ref. } & 3.01(1.26) & \text { Ref. } & 2.19(0.73) & \text { Ref. } \\ 7.0 & 3.21(1.19) & .12^{* \star *} & 2.75(1.30) & -.05^{\star} & 2.58(0.72) & .13^{* \star *} \\ 16.2 & 2.19(1.05) & -.15^{* *} & 3.53(1.37) & .15^{* * *} & 1.70(0.61) & -.24^{* \star} \\ & & & & & & \\ 62.5 & 2.57(1.14) & \text { Ref. } & 3.12(1.31) & \text { Ref. } & 2.11(0.75) & \text { Ref. } \\ 37.5 & 2.70(1.19) & .05^{*} & 3.00(1.28) & -.04^{*} & 2.18(0.72) & .04\end{array}$

$\begin{array}{lllllll}68.0 & 2.44(1.11) & \text { Ref. } & 3.22(1.31) & \text { Ref. } & 2.00(0.71) & \text { Ref. } \\ 32.0 & 3.00(1.18) & .22^{\star \star *} & 2.76(1.23) & -.17^{\star \star *} & 2.42(0.73) & .26^{\star * *}\end{array}$

$77.72 .49(1.12) \quad$ Ref. $3.19(1.31)$ Ref. $2.06(0.72)$ Ref.

$22.3 \quad 3.06(1.19) \quad .20^{* * *} \quad 2.67(1.20) \quad-.17^{* * *} \quad 2.42(0.73) \quad .20^{* * *}$

$\begin{array}{lllllll}39.7 & 2.33(1.13) & \text { Ref. } & 3.31(1.35) & \text { Ref. } & 1.93(0.71) & \text { Ref. } \\ 23.5 & 2.54(1.09) & .08^{* *} & 3.03(1.30) & -.09^{\star * *} & 2.08(0.69) & .09^{\star * *} \\ 37.8 & 2.98(1.14) & .27^{* * *} & 2.85(1.19) & -.17^{\star * *} & 2.40(0.72) & .30^{\star * *}\end{array}$




$$
\text { No }
$$

Yes

Number of male sex partners in

past $6 \mathrm{~m}$

None

$1-10$

More than 10

Alcohol use (AUDIT-C)

Abstinent

Low risk

Moderate risk

High risk

Any illicit drug use

\section{Never \\ Not in past $6 \mathrm{~m}$}

Less than monthly in past $6 \mathrm{~m}$

Monthly to weekly in past $6 \mathrm{~m}$

At least weekly in past $6 \mathrm{~m}$

Crystal methamphetamine use

$\begin{array}{lllllll}63.4 & 2.39(1.09) & \text { Ref. } & 3.22(1.33) & \text { Ref. } & 1.99(0.72) & \text { Ref. } \\ 36.6 & 3.01(1.18) & .26^{\star * *} & 2.82(1.19) & -.15^{\star \star *} & 2.40(0.71) & .27^{\star * *}\end{array}$

$\begin{array}{rllllll}8.8 & 2.08(0.98) & \text { Ref. } & 3.42(1.46) & \text { Ref. } & 1.82(0.72) & \text { Ref. } \\ 53.5 & 2.48(1.13) & .17^{* * *} & 3.17(1.30) & -.10^{*} & 2.01(0.70) & .13^{* *} \\ 37.7 & 2.94(1.16) & .36^{* \star *} & 2.86(1.22) & -.21^{* * *} & 2.40(0.72) & .38^{\star * *}\end{array}$

$\begin{array}{rrrrlll}5.8 & 2.01(0.97) & \text { Ref. } & 3.74(1.45) & \text { Ref. } & 1.85(0.82) & \text { Ref. } \\ 38.3 & 2.36(1.16) & .15^{\star *} & 3.32(1.35) & -.16^{\star *} & 1.96(0.73) & .07 \\ 45.1 & 2.79(1.12) & .34^{\star * *} & 2.90(1.21) & -.32^{\star \star *} & 2.26(0.69) & .27^{\star * *} \\ 10.7 & 3.14(1.09) & .30^{\star \star *} & 2.56(1.08) & -.28^{\star \star *} & 2.44(0.70) & .24^{\star \star *}\end{array}$

\begin{tabular}{|c|c|c|c|c|c|c|}
\hline 14.1 & $1.42(0.48)$ & Ref. & $4.32(1.22)$ & Ref. & $1.41(0.47)$ & Ref. \\
\hline 24.9 & $2.18(0.99)$ & $.28^{* * *}$ & $3.34(1.26)$ & $-.33^{* \star *}$ & $1.89(0.62)$ & $28^{\star * *}$ \\
\hline 25.3 & $2.69(1.04)$ & $.47^{* * *}$ & $2.86(1.19)$ & $-.49^{* \star *}$ & $2.22(0.68)$ & $.48^{* \star *}$ \\
\hline 18.7 & $3.26(1.04)$ & $.62^{* * *}$ & $2.57(1.08)$ & $-.52^{* * *}$ & $2.54(0.67)$ & $60^{* * *}$ \\
\hline 17.0 & $3.44(0.98)$ & $.65^{\star \star \star}$ & $2.53(0.98)$ & $-.52^{\star \star \star}$ & $2.54(0.65)$ & $57^{\star \star \star}$ \\
\hline
\end{tabular}




\begin{tabular}{|c|c|c|c|c|c|c|c|}
\hline Never & 72.1 & $2.26(1.04)$ & Ref. & $3.34(1.32)$ & Ref. & $1.90(0.64)$ & Ref. \\
\hline Not in past $6 \mathrm{~m}$ & 14.2 & $3.34(0.97)$ & $.32^{* * *}$ & $2.38(0.97)$ & $-.26^{\star \star \star}$ & $2.62(0.61)$ & $.34^{* * *}$ \\
\hline Less than monthly in past $6 \mathrm{~m}$ & 7.6 & $3.60(0.87)$ & $.31^{* * *}$ & $2.31(0.90)$ & $-.21^{* \star \star}$ & $2.83(0.57)$ & $.33^{* * *}$ \\
\hline Monthly to weekly in past $6 \mathrm{~m}$ & 4.2 & $3.95(0.76)$ & $.29^{* \star *}$ & $2.30(0.91)$ & $-.16^{* * *}$ & $2.97(0.50)$ & $.29^{* * *}$ \\
\hline At least weekly in past $6 \mathrm{~m}$ & 2.0 & $3.94(0.80)$ & $.20^{* * *}$ & $2.63(0.91)$ & $-.08^{\star \star *}$ & $3.04(0.49)$ & $.22^{* \star *}$ \\
\hline
\end{tabular}

Self-perceived current problem with drug use

No

Yes

Drug use for sex in past $6 \mathrm{~m}$

$\begin{array}{llllllll}\text { No } & 79.4 & 2.32(1.05) & \text { Ref. } & 3.27(1.32) & \text { Ref. } & 1.96(0.68) & \text { Ref. } \\ \text { Yes } & 20.6 & 3.76(0.83) & .50^{* \star *} & 2.32(0.90) & -.30^{\star * \star} & 2.83(0.52) & .48^{* * \star}\end{array}$

${ }^{*} \mathrm{p}<.05 ;{ }^{* *} \mathrm{p}<.01 ;{ }^{* \star *} \mathrm{p}<.001 .6 \mathrm{~m}, 6$ months; AUDIT-C, Alcohol Use Disorders Identification Test - Consumption questions; GHB, gamma-hydroxybutyrate; $\beta$ standardised beta.

Drug use for social and sexual enhancement scale: Mean scores ranged from 1 (strongly disagree) to 6 (strongly agree). Perceptions of drug risk scale: Mean scores ranged from 1 (strongly agree) to 6 (strongly disagree). Acceptability of drug use among gay friends scale: Mean scores ranged from 1 (not at all accepting) to 4 (very accepting). 
Table 5. Logistic regression analyses examining associations between illicit drug use and scales measuring drug use for social and sexual enhancement, perceptions of drug risk, and acceptability of drug use among gay friends

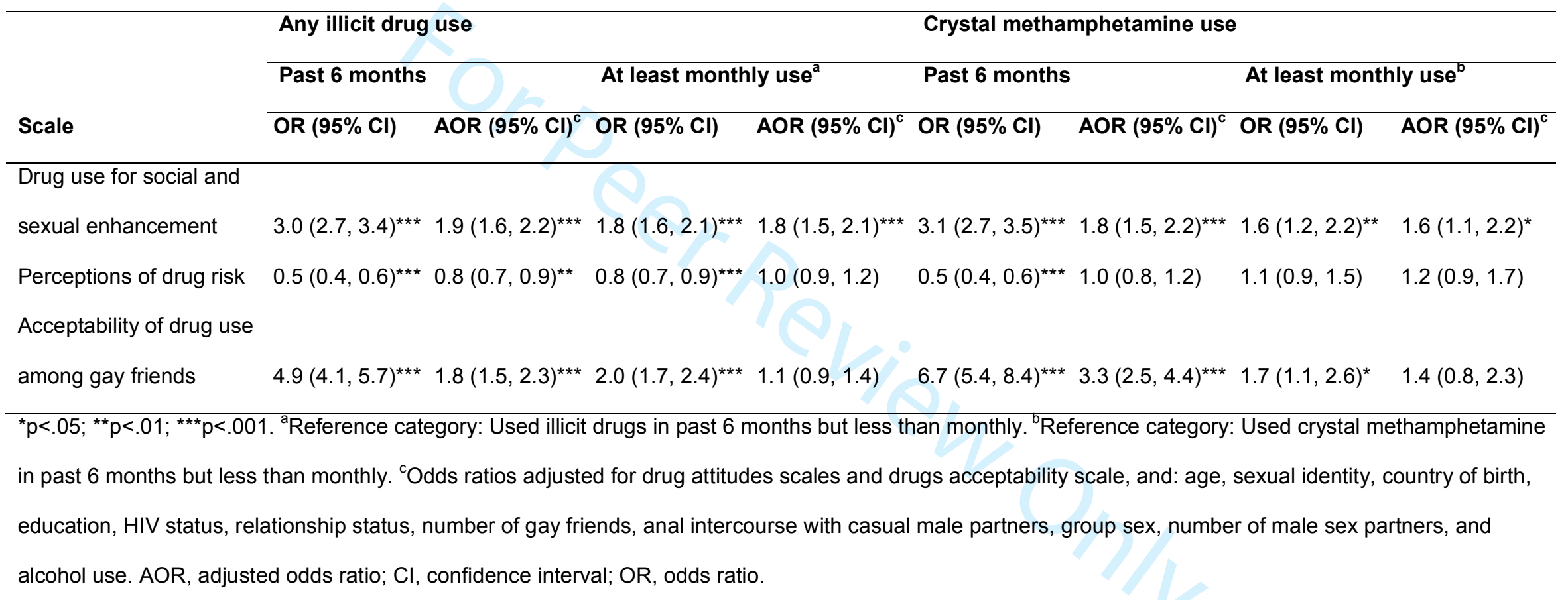




\section{References}

AlHW. (2017). National Drug Strategy Household Survey 2016: detailed findings. Drug Statistics series no. 31. Cat. no. PHE 214. Canberra: Australian Institute of Health and Welfare.

Ajzen, I. (1991). The theory of planned behavior. Organizational behavior and human decision processes, 50, 179-211.

Bourne, A., Reid, D., Hickson, F., Torres-Rueda, S., \& Weatherburn, P. (2015). Illicit drug use in sexual settings ('chemsex') and HIVISTI transmission risk behaviour among gay men in South London: findings from a qualitative study. Sex Transm Infect, 91, 564-568.

Bryant, J., Ellard, J., Fisher, D., \& Treloar, C. (2012). The exposure and transition study: exposure to injecting and hepatitis $C$ among young people at risk. Sydney: National Centre in HIV Social Research, UNSW.

Bryant, J., Hopwood, M., Dowsett, G. W., Aggleton, P., Holt, M., Lea, T., . . Treloar, C. (2018). The rush to risk when interrogating the relationship between methamphetamine use and sexual practice among gay and bisexual men. International Journal of Drug Policy, 55, 242-248.

Carpiano, R. M., Kelly, B. C., Easterbrook, A., \& Parsons, J. T. (2011). Community and drug use among gay men: the role of neighborhoods and networks. Journal of Health and Social Behavior, 52, 74-90.

Chalmers, J., Lancaster, K., \& Hughes, C. (2016). The stigmatisation of 'ice'and underreporting of meth/amphetamine use in general population surveys: a case study from Australia. International Journal of Drug Policy, 36, 15-24.

Cochran, S. D., Grella, C. E., \& Mays, V. M. (2012). Do substance use norms and perceived drug availability mediate sexual orientation differences in patterns of substance use? Results from the California Quality of Life Survey II. Journal of Studies on Alcohol and Drugs, $73,675-685$. 
D'Emilio, J. (1983). Sexual politics, sexual communities: The making of a homosexual minority in the United States, 1940-1970. Chicago: University of Chicago Press.

Dwyer, R. (2008). Privileging pleasure: Temazepam injection in a heroin marketplace. International Journal of Drug Policy, 19, 367-374.

Faderman, L. (1992). Odd girls and twilight lovers: A history of lesbian life in TwentiethCentury America. New York: Penguin.

Flora, D. B., \& Curran, P. J. (2004). An empirical evaluation of alternative methods of estimation for confirmatory factor analysis with ordinal data. Psychological methods, 9, 466-491.

Green, A. I., \& Halkitis, P. N. (2006). Crystal methamphetamine and sexual sociality in an urban gay subculture: An elective affinity. Culture, Health and Sexuality, 8, 317-333.

Halkitis, P. N., Mukherjee, P. P., \& Palamar, J. J. (2007). Multi-level modeling to explain methamphetamine use among gay and bisexual men. Addiction, 102, 76-83.

Hamilton, C. J., \& Mahalik, J. R. (2009). Minority stress, masculinity, and social norms predicting gay men's health risk behaviors. Journal of Counseling Psychology, 56, 132.

Hammoud, M. A., Bourne, A., Maher, L., Jin, F., Haire, B., Lea, T., . . Prestage, G. (2018). Intensive sex partying with gamma-hydroxybutyrate: factors associated with using gamma-hydroxybutyrate for chemsex among Australian gay and bisexual menresults from the Flux Study. Sexual Health, 15, 123-134.

Harris, A. H., Bradley, K. A., Bowe, T., Henderson, P., \& Moos, R. (2010). Associations between AUDIT-C and mortality vary by age and sex. Population Health Management, 13, 263-268.

Holt, M., Lea, T., Mao, L., Zablotska, I., Lee, E., Hull, P., . . Prestage, G. (2017). Adapting behavioural surveillance to antiretroviral-based HIV prevention: reviewing and anticipating trends in the Australian Gay Community Periodic Surveys. Sexual Health, $14,72-79$. 
Hurley, M., \& Prestage, G. (2009). Intensive sex partying amongst gay men in Sydney. Culture, health \& sexuality, 11, 597-610.

Isaiah Green, A. (2003). " chem friendly": the institutional basis of" club-drug" use in a sample of urban gay men. Deviant Behavior, 24, 427-447.

Kalichman, S. C., \& Rompa, D. (1995). Sexual sensation seeking and sexual compulsivity scales: validity, and predicting HIV risk behavior. Journal of personality assessment, $65,586-601$.

Lea, T., Mao, L., Hopwood, M., Prestage, G., Zablotska, I., de Wit, J., \& Holt, M. (2016). Methamphetamine use among gay and bisexual men in Australia: trends in recent and regular use from the Gay Community Periodic Surveys. International Journal of Drug Policy, 29, 66-72.

Lea, T., Prestage, G., Mao, L., Zablotska, I., Wit, J., \& Holt, M. (2013). Trends in drug use among gay and bisexual men in Sydney, Melbourne and Queensland, Australia. Drug and Alcohol Review, 32, 39-46.

Lewis, L. A., \& Ross, M. W. (1995). A select body: The gay dance party subculture and the HIVIAIDS pandemic. London: Cassell.

Lloyd, C. (2013). The stigmatization of problem drug users: A narrative literature review. Drugs: Education, Prevention and Policy, 20, 85-95.

Mahalik, J. R., Burns, S. M., \& Syzdek, M. (2007). Masculinity and perceived normative health behaviors as predictors of men's health behaviors. Social Science \& Medicine, $64,2201-2209$.

Mansergh, G., Colfax, G. N., Marks, G., Rader, M., Guzman, R., \& Buchbinder, S. (2001). The Circuit Party Men's Health Survey: findings and implications for gay and bisexual men. American journal of public health, 91, 953-958.

McCabe, S. E., Hughes, T. L., Bostwick, W. B., West, B. T., \& Boyd, C. J. (2009). Sexual orientation, substance use behaviors and substance dependence in the United States. Addiction, 104, 1333-1345. 
Meyer, I. H. (2003). Prejudice, social stress, and mental health in lesbian, gay, and bisexual populations: conceptual issues and research evidence. Psychological bulletin, 129, 674-697.

Olsen, A. (2009). Consuming e: ecstasy use and contemporary social life. Contemporary Drug Problems, 36, 175-191.

Pennay, A., \& Moore, D. (2010). Exploring the micro-politics of normalisation: Narratives of pleasure, self-control and desire in a sample of young Australian 'party drug'users. Addiction Research \& Theory, 18, 557-571.

Peterson, J. L., \& Bakeman, R. (2006). Impact of beliefs about HIV treatment and peer condom norms on risky sexual behavior among gay and bisexual men. Journal of Community Psychology, 34, 37-46.

Power, J., Mikołajczak, G., Bourne, A., Brown, G., Leonard, W., Lyons, A., . . Lucke, J. (2018). Sex, drugs and social connectedness: wellbeing among HIV-positive gay and bisexual men who use party-and-play drugs. Sexual Health, 15, 135-143.

Prestage, G., Hammoud, M., Lea, T., Jin, F., \& Maher, L. (2017). Measuring drug use sensation-seeking among Australian gay and bisexual men. International Journal of Drug Policy, 49, 73-79.

Prestage, G., Hudson, J., Down, I., Bradley, J., Corrigan, N., Hurley, M., . . Mclnnes, D. (2009). Gay men who engage in group sex are at increased risk of HIV infection and onward transmission. AIDS and Behavior, 13, 724.

Race, K. (2009). Pleasure consuming medicine: the queer politics of drugs. Durham: Duke University Press.

Race, K., Lea, T., Murphy, D., \& Pienaar, K. (2017). The future of drugs: recreational drug use and sexual health among gay and other men who have sex with men. Sexual Health, 14, 42-50.

Reback, C. J. (1997). The social construction of a gay drug: methamphetamine use among gay and bisexual males in Los Angeles. Los Angeles, CA: City of Los Angeles. 
Reynolds, R. (2002). From camp to queer: re-making the Australian homosexual. Carlton South: Melbourne University Press.

Ross, M. W., Mattison, A. M., \& Franklin Jr, D. R. (2003). Club drugs and sex on drugs are associated with different motivations for gay circuit party attendance in men. Substance Use and Misuse, 38, 1173-1183.

Roxburgh, A., Lea, T., de Wit, J., \& Degenhardt, L. (2016). Sexual identity and prevalence of alcohol and other drug use among Australians in the general population. International Journal of Drug Policy, 28, 76-82.

Sayette, M. A., Creswell, K. G., Dimoff, J. D., Fairbairn, C. E., Cohn, J. F., Heckman, B. W., . .. Moreland, R. L. (2012). Alcohol and group formation: A multimodal investigation of the effects of alcohol on emotion and social bonding. Psychological science, 23, 869878.

Scheibe, L. (2017). Visualising "junkies" and "meth heads": a visual analysis of the persistent negative reputation of heroin and meth users. Drugs and Alcohol Today, 17, 40-49.

Schwartz, J., \& Willis, A. (2009). Coverage of methamphetamine in GLBT newspapers. Mass Communication and Society, 13, 30-47.

Southgate, E., \& Hopwood, M. (2001). The role of folk pharmacology and lay experts in harm reduction: Sydney gay drug using networks. International Journal of Drug Policy, 12, 321-335.

Stardust, Z., Kolstee, J., Joksic, S., Gray, J., \& Hannan, S. (2018). A community-led, harmreduction approach to chemsex: case study from Australia's largest gay city. Sexual Health.

Wotherspoon, G. (1991). City of the plain: History of a gay sub-culture. Sydney: Hale \& Iremonger. 